Geografia e Ordenamento do Território, Revista Electrónica

Centro de Estudos de Geografia e Ordenamento do Território

http://cegot.org

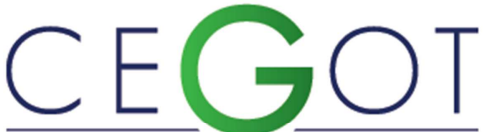

Centro de Estudos de Geografia e Ordenamento do Território
ISSN :2182-1267

Freire Correia, $\mathrm{M}$.

IGOT-UL / CEG

miguelcorreia@campus.ul.pt

\title{
Clima e olivicultura. Potencialidades locais na região de Alvega
}

Referência: Freire Correia, M. (2014). Clima e olivicultura. Potencialidades locais na região de Alvega. Revista de Geografia e Ordenamento do Território (GOT), n.o 5 (junho). Centro de Estudos de Geografia e Ordenamento do Território, p. 117-142

\section{Resumo}

O solo e o clima regional influenciam os mecanismos fisiológicos da oliveira (Olea europaea L.) com reflexo na produção oleícola e na potencial localização dos olivais; esta depende também das modificações do clima local, ainda pouco conhecidas, nas suas vertentes aplicadas. $O$ objetivo da presente investigação é ensaiar uma metodologia de avaliação das potencialidades agroclimáticas locais para a olivicultura na região de Alvega passível de extrapolação para outras culturas agrícolas e regiões. A metodologia assenta na espacialização da aptidão e dos constrangimentos agroclimáticos locais da olivicultura. A carta das potencialidades olivícolas de origem climática local na região de Alvega constitui uma ferramenta passível de aplicação no ordenamento, planeamento e gestão agrícola do território.

Palavras-chave: climas locais, olivicultura, potencialidades agroclimáticas, ordenamento agrícola do território, região de Alvega. 


\section{Abstract}

The regional soil and climate influence the physiological mechanisms of the olive tree (Olea europaea L.) as reflected in their oil production and the potential location of olive groves; that also depends on the local climate changes, still little known in its applied aspects. The purpose of this research is to test a methodology for assessing the local agroclimatic potential for oliviculture in the Alvega region capable of extrapolation to other crops and regions. The methodology is based on the spatial distribution of the local agroclimatic suitability and constraints of oliviculture. The map of local agroclimatic potential for oliviculture in the Alvega region is a tool that can be applied in spatial planning and management of agricultural land.

Keywords: local climates, oliviculture, agroclimatic potentialities, agricultural spatial planning, Alvega region.

\section{Introdução}

O clima influencia a fisiologia da oliveira (Olea europaea L.) com reflexo na quantidade e qualidade da azeitona e do azeite (García, 2005; Barranco et al., 2008). Assim, a oliveira apresenta exigências climáticas capazes de serem satisfeitas por determinados climas, os quais determinam a sua localização. Por seu lado, os elementos do clima que condicionam a olivicultura dependem de diferentes fatores geográficos. No seio de um território caracterizado por determinado clima regional ou mesoclima (influenciado pela latitude, distância ao litoral, altitude, relevo e exposição às massas de ar), as características da topografia e da superfície terrestre originam um mosaico complexo de climas locais (Alcoforado et al., 1993; Barry, 1994; Geiger et al., 2003, Mora, 2006). A escala local faz a transição entre a mesoescala e a microescala na organização dos estudos do clima (Oke, 1996). Deste modo, a escala climática local adequa-se ao estudo de fenómenos com expressão espacial variável entre $100 \mathrm{~m}$ e os $50 \mathrm{~km}$ (Oke, 1996) e espessura entre 1 e 2 km (Garratt, 1994). Em termos temporais, os fenómenos meteorológicos a esta escala desenvolvem-se em algumas horas ou alguns meses (Oke, 1996). No entanto, este autor adverte para o facto dos fenómenos meteorológicos estarem interligados constituindo um continuum. Assim, a escala local afigura-se mais adequada aos estudos agroclimáticos uma vez que oferece a possibilidade de "reconhecer e estudar as influências dos fatores geográficos locais, que geram por vezes grandes diferenças nas características climáticas em pequenas áreas" (Mora, 1998) com 
reflexo nas potencialidades agrícolas. A tipologia de informação contida nos estudos de agroclimatologia local é aquela que se manifesta passível de utilização por agricultores e técnicos no ordenamento, planeamento e gestão agrícola do território. Curiosamente, os estudos do clima à escala local nasceram da necessidade na agricultura de conhecer as características climáticas da camada de ar junto ao solo e sua variabilidade espáciotemporal (Mora, 1998).

Porém, a maioria das metodologias de avaliação das potencialidades agrícolas de origem climática empregues nos estudos agroclimáticos, utilizam os registos das observações meteorológicas das estações das redes de mesoescala como representativos dos locais de instalação das culturas agrícolas e/ou, recorrem a índices bioclimáticos, a maioria dos quais, concebidos para refletir apenas a influência dos fatores geográficos regionais.

O objetivo da presente investigação é ensaiar uma metodologia de avaliação das potencialidades agroclimáticas locais à olivicultura na região de Alvega (Fig. 1), passível de extrapolação para outras culturas agrícolas e regiões.

Desde tempos imemoriais que a olivicultura tem importante peso social e económico na região de Alvega (Patrão, 2003). Atualmente, a área em estudo insere-se no contexto da região olivícola Ribatejo e Oeste (Azeites Ribatejo DOP), a qual integra a 'zona com grande vocação olivícola', nomeadamente regiões que reúnem as condições mais favoráveis ao desenvolvimento e à produtividade do olival a nível nacional (Böhm, 2013). Entre essas condições, destaca-se a influência do mesoclima mediterrâneo. No entanto, as características da topografia e da superfície terrestre na região de Alvega originam um mosaico de climas locais (Correia, 2011), os quais revelam diferentes potencialidades agroclimáticas à olivicultura. Deste modo, o controlo exercido sobre o clima pelos fatores geográficos locais combinado com os requisitos climáticos da oliveira conduz à definição de um padrão territorial de potencialidades agroclimáticas. 


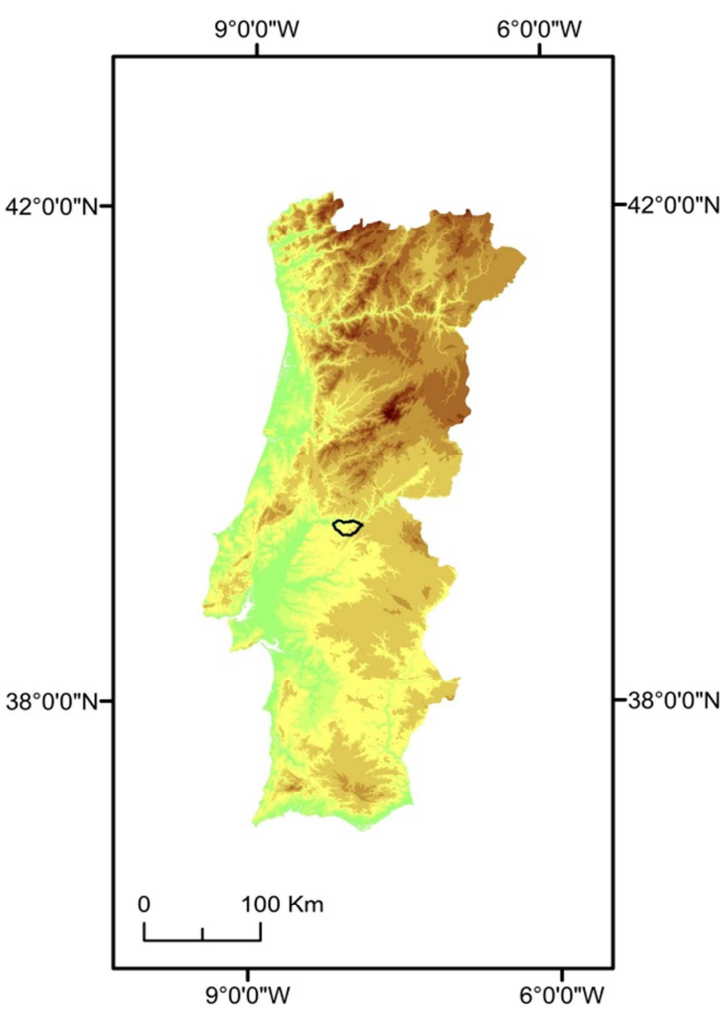

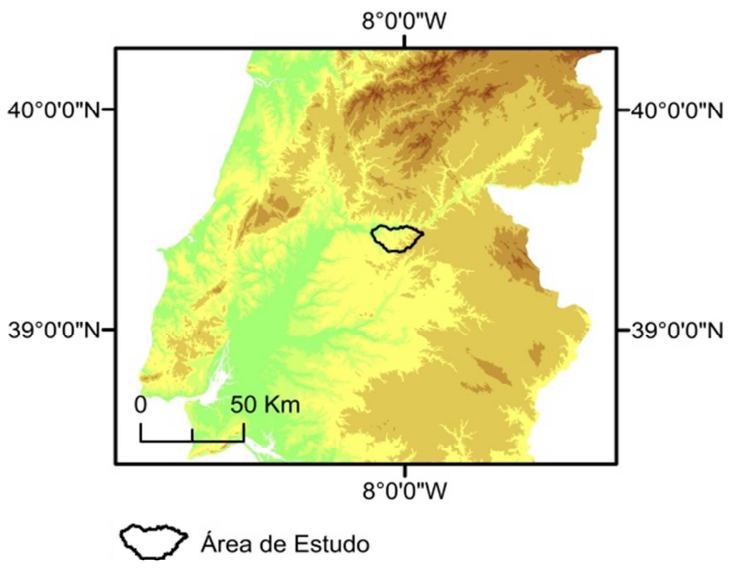

Hipsometria

Altitude (m)

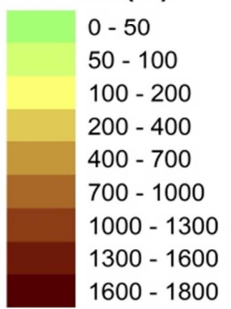

Sistema de Projecção Hayford-Gauss Datum Lisboa

Fig. 1 - Enquadramento geográfico da região de Alvega.

\section{Metodologia}

A avaliação das potencialidades olivícolas na região de Alvega assenta na caracterização e distribuição da aptidão e dos constrangimentos agroclimáticos locais, os quais refletem o grau de satisfação dos requisitos climáticos da oliveira por parte dos climas locais. Estes dependem, essencialmente, das condições topográficas pelo que a Carta das Unidades de Relevo da Região de Alvega (Fig. 2), constituída por cinco classes representativas das formas de relevo dominantes, traduz as diferenças climáticas à escala local. 


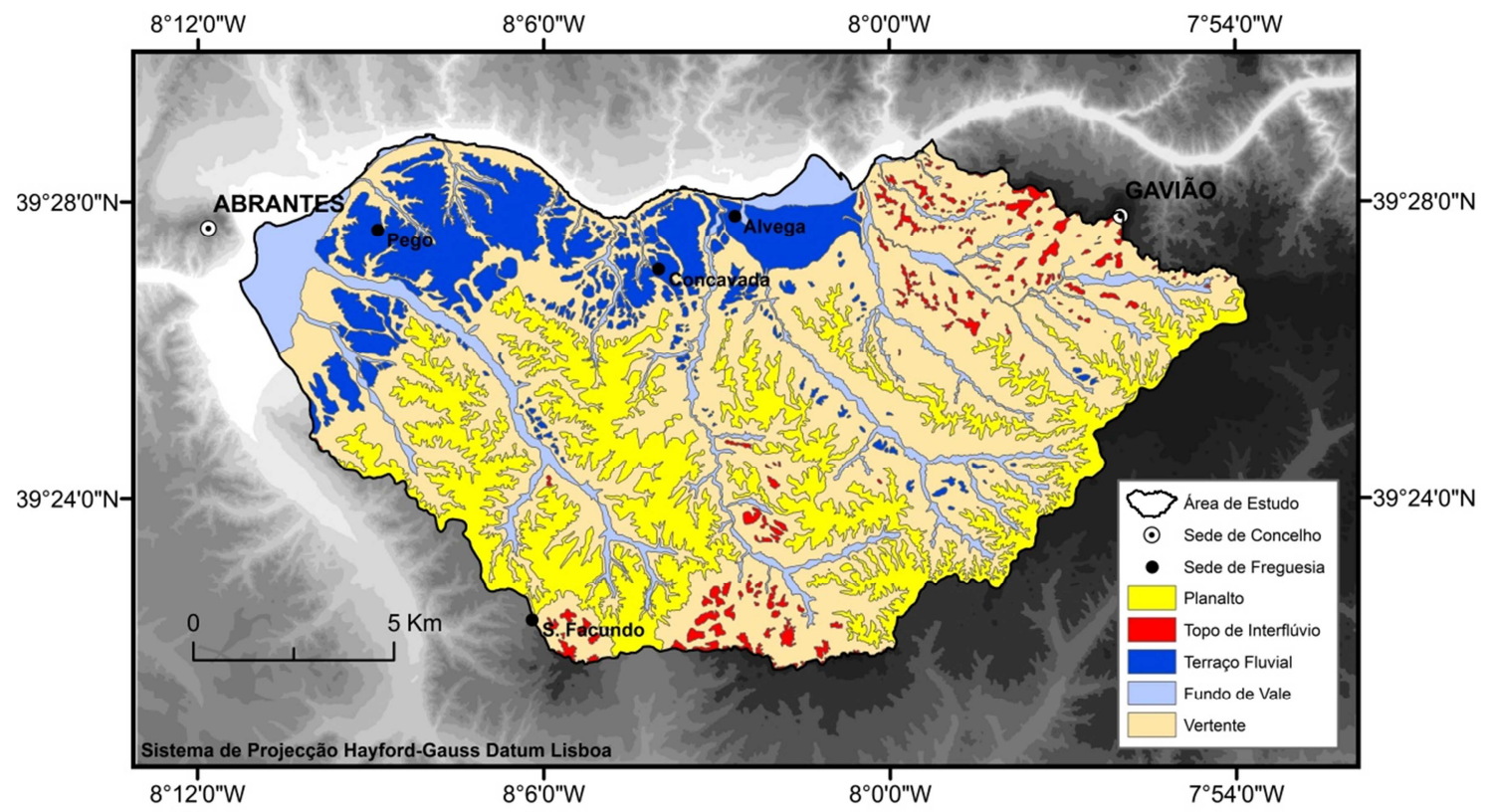

Fig. 2 - Carta das Unidades de Relevo da Região de Alvega.

A aptidão e os constrangimentos agroclimáticos locais à olivicultura são definidos com base nas condições favoráveis ou limitantes e na suscetibilidade aos acidentes agroclimáticos. As condições agroclimáticas locais favoráveis ou limitantes à olivicultura são analisadas a partir da a) modelação da radiação solar (potencial) e da duração da insolação, no período da floração; b) avaliação das condições térmicas ao longo do ciclo biológico anual; c) cálculo das datas médias de início da floração; d) síntese cartográfica da perigosidade de geadas de irradiação; e) análise dos contrastes da precipitação média anual; f) interpretação da potencial geração de sistemas de ventos locais de origem térmica e de distorções no rumo e na velocidade do vento dos sistemas de circulação regionais originadas pela morfologia do terreno. A suscetibilidade local aos acidentes agroclimáticos da olivicultura é avaliada com base na a) frequência e intensidade dos elementos ou fenómenos climáticos desencadeantes; b) na cartografia efetuada no âmbito da análise das condições agroclimáticas locais favoráveis ou limitantes à olivicultura.

\subsection{Informação Climática Utilizada}

No âmbito da análise das condições agroclimáticas locais favoráveis ou limitantes à olivicultura na região de Alvega foram a) avaliadas as condições térmicas ao longo do 
ciclo biológico anual da oliveira com base em registos da temperatura média diária do ar das estações (CTP, Gavião, Pego, S. Facundo) da rede meteorológica da PEGOP, SA (Fig. 3 e Quadro 1) consideradas representativas do relevo; b) calculadas as datas médias de início da floração da oliveira com base em registos da temperatura média diária do ar das estações (CTP, Gavião, Pego, S. Facundo) da rede meteorológica da PEGOP, SA (Fig. 3 e Quadro 1) consideradas representativas do relevo; c) sintetizada cartograficamente a perigosidade local às geadas de irradiação a partir do estudo dos padrões das temperaturas mínimas diárias do ar em diferentes condições de estabilidade atmosférica (Correia, 2011) realizado com base nos valores registados às $8 \mathrm{~h}$ (hora de maior frequência de ocorrência da temperatura mínima diária do ar) nos postos termométricos (Alto do Termo, Coalhos, Entrudo, Montes Cimeiros, Pedregulho, Represa) instalados em dois perfis topográficos transversais aos vales selecionados considerados representativos do relevo (Fig. 3 e Quadro 1); d) analisados os contrastes locais da precipitação média anual com base nos registos das precipitações da estação (Abrantes - Concavada) e dos postos (Bemposta, Gavião, Margem) da rede meteorológica do INAG, IP considerados representativos do relevo (Fig. 3 e Quadro 1); e) interpretada a potencial geração de sistemas de ventos locais de origem térmica e de distorções locais no rumo e na velocidade do vento dos sistemas de circulação regionais originadas pela morfologia do terreno com base nos registos do rumo e da velocidade do vento diários nas diversas estações (CTP, Gavião, Pego, S. Facundo) da rede meteorológica da PEGOP, SA existentes na região (Fig. 3 e Quadro 1). Os registos do vento apenas são representativos dos locais de instalação das estações meteorológicas.

No âmbito da avaliação da suscetibilidade local da região de Alvega aos acidentes agroclimáticos da olivicultura analisaram-se a) as frequências e intensidade dos elementos ou fenómenos climáticos desencadeantes com base, nos registos do número de dias/ano da temperatura mínima do ar $<0^{\circ} \mathrm{C}$, temperatura máxima do ar $>35^{\circ} \mathrm{C}$, geada, neve, granizo e insolação publicados no Anuário Climatológico de Portugal (IPMA, IP) referentes à estação de Alvega (Fig. 3 e Quadro 1 - em anexo) e, na análise estatística dos valores máximos no ano da quantidade diária de precipitação em Portugal Continental para a estação meteorológica de Alvega e posto udométrico de Gavião (Rocha Faria et al., 1979) publicada no fascículo O Clima de Portugal; b) a cartografia efetuada no âmbito da análise das condições agroclimáticas locais favoráveis ou limitantes à olivicultura (radiação solar potencial; duração da insolação; perigo de geada de irradiação). 


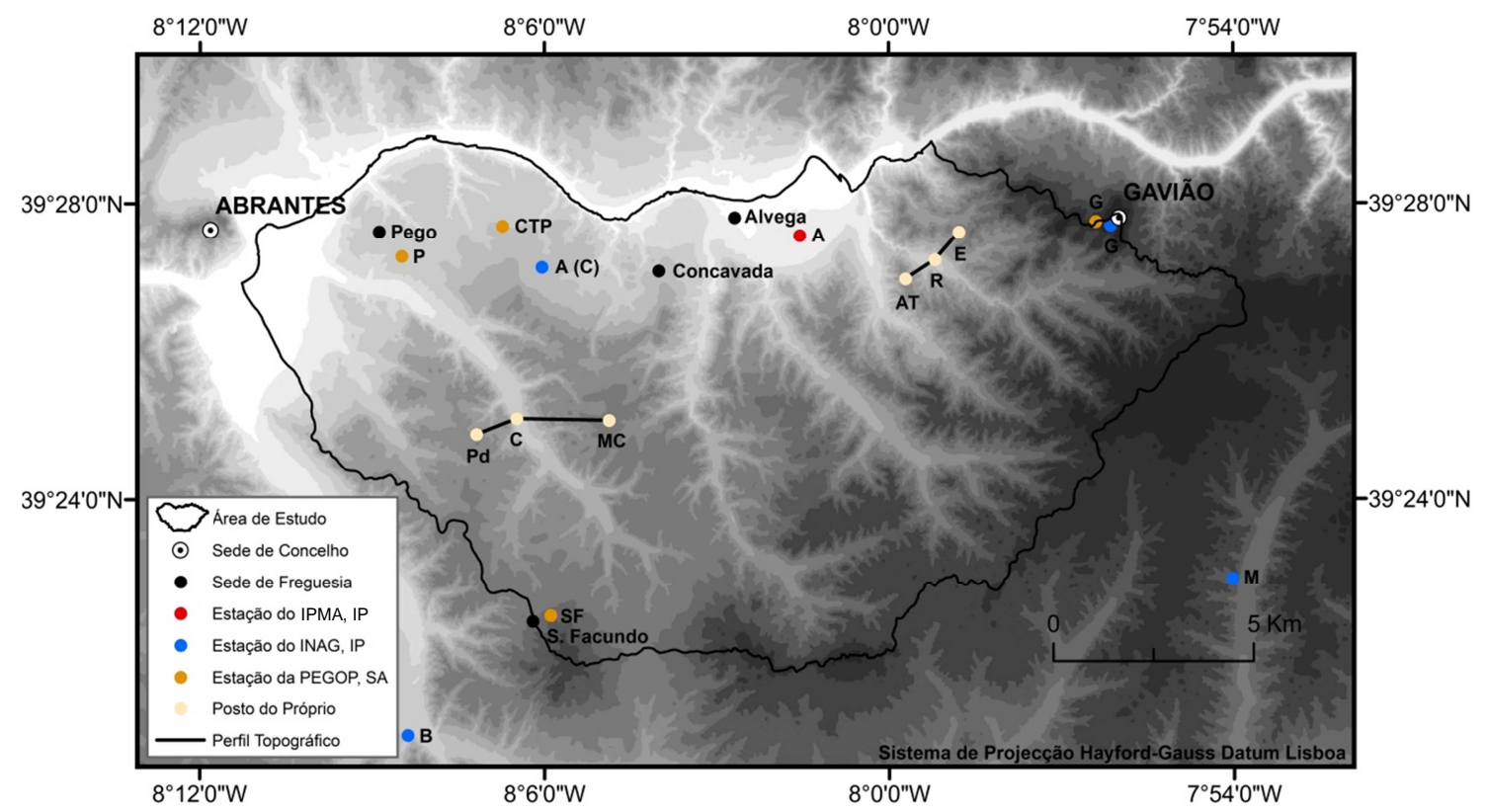

Fig. 3 - Localização das estações meteorológicas, postos udométricos e termométricos automáticos na região de Alvega e envolvente próxima e dos perfis de observações itinerantes (A - Alvega, AT - Alto do Termo, B - Bemposta, C - Coalhos, A (C) - Abrantes (Concavada), CTP Central Termoelétrica do Pego, E - Entrudo, G - Gavião, M - Margem, MC - Montes Cimeiros, P Pego, Pd - Pedregulho, R - Represa).

\subsection{Condições Agroclimáticas Locais Favoráveis ou Limitantes à Olivicultura}

\subsubsection{Radiação Solar e Insolação}

A radiação solar e a insolação constituem os elementos mais importantes do clima olivícola. O local de implantação de um olival deve oferecer boas condições de exposição aos raios solares e de luminosidade, como condições indispensáveis a uma eficaz realização da fotossíntese. Estas variáveis dependem da latitude, da época do ano e da ocultação do horizonte pelos obstáculos. A Carta da Radiação Solar Potencial na Região de Alvega (Fig. 4) e a Carta da Duração da Insolação na Região de Alvega (Fig. 5), para o período de Maio a Junho (período em que decorre floração, uma das mais importantes fases fenológicas do ciclo biológico anual da oliveira), foram construídas em ambiente SIG através do software SagaGis 2.0.4 (Open Source) que contém o módulo de cálculo de modelos de sombra. No período de Maio a Junho, a região de Alvega apresenta um potencial de radiação solar variável entre 199.192 e $514.072 \mathrm{KJ} / \mathrm{m}^{2}$ (Fig. 4) e um 
potencial de insolação variável entre 76.5 e 193 horas (Fig. 5). À exceção da área ocupada pelas vertentes, as restantes áreas da região de Alvega manifestam médios a elevados valores de radiação solar e de insolação (Fig. 4 e Fig. 5).

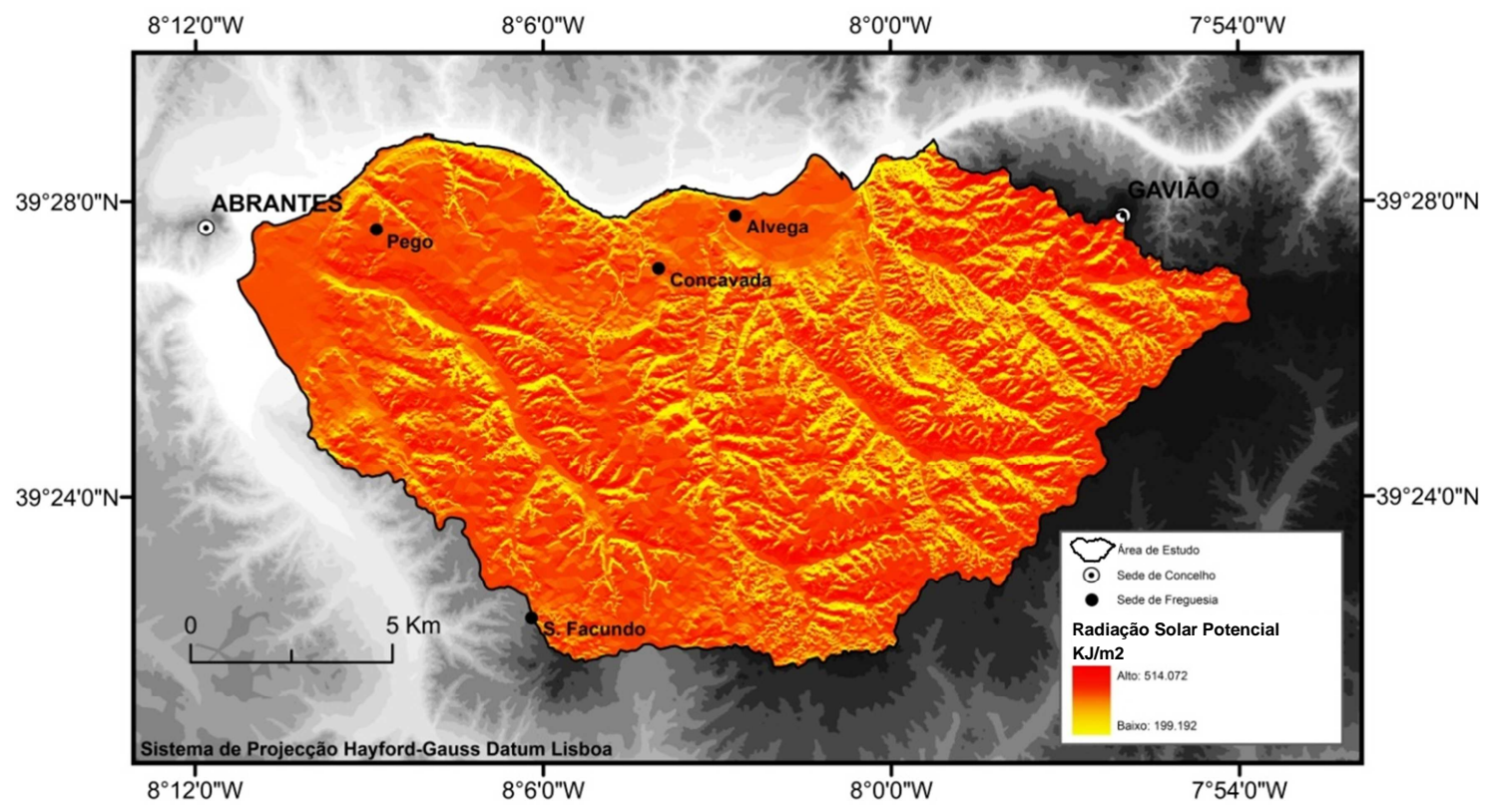

Fig. 4 - Carta da Radiação Solar Potencial (média diária de Maio a Junho) na Região de Alvega.

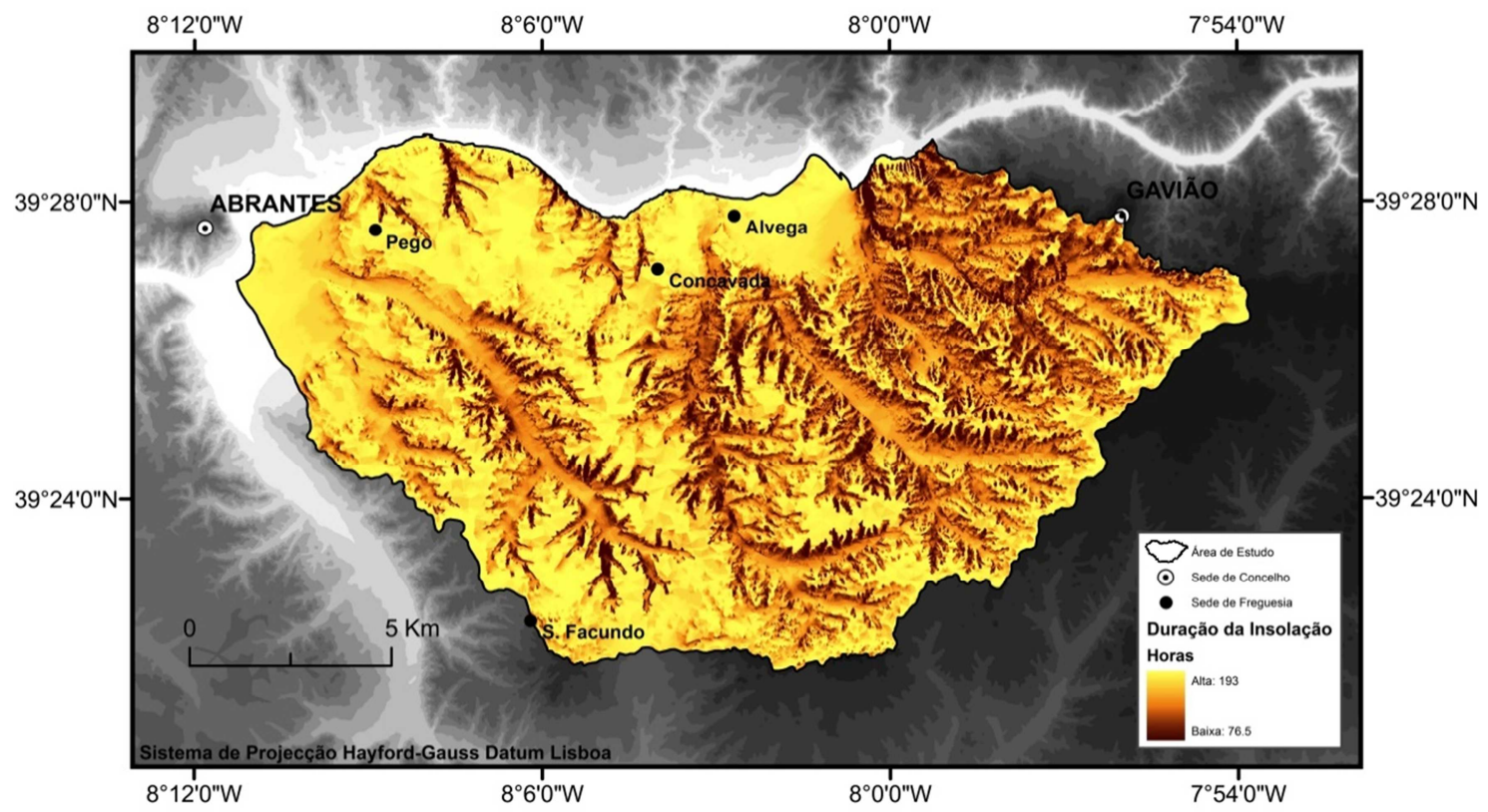

Fig. 5 - Carta da Duração da Insolação (média de Maio a Junho) na Região de Alvega. 


\subsubsection{Temperatura do Ar}

\section{a) Temperatura do Ar e Ciclo Biológico da Oliveira}

Para se compreender alguns aspetos relativos à fenologia da oliveira na região de Alvega, procedeu-se ao cálculo das datas médias de início das fases fenológicas do seu ciclo biológico anual nos diversos climas locais através do método das temperaturas acumuladas (Quadro 2). De acordo com Francolini (In Jaraquemada, 1977) considera-se, para a oliveira, a temperatura-base de $10{ }^{\circ} \mathrm{C}$. Deste modo, o número de graus de crescimento em cada dia resulta da subtração da temperatura-base à temperatura média do dia, quando o valor é igual ou superior a $10{ }^{\circ} \mathrm{C}$ (temperatura à qual se interrompe o repouso vegetativo da oliveira) durante dez dias consecutivos. Os aspetos inerentes ao escaldão foram tidos em consideração no cálculo das datas, uma vez que temperaturas demasiado elevadas prejudicam a planta (Feio, 1991). De acordo com Francolini (In Jaraquemada, 1977), para a oliveira, o limite acima do qual não se contabilizam as temperaturas é de $35{ }^{\circ} \mathrm{C}$. Os limiares (a partir do início da atividade vegetativa) das temperaturas acumuladas nas distintas fases fenológicas do ciclo biológico anual da oliveira empregues são os propostos por Francolini (In Jaraquemada, 1977). Refira-se que as datas apresentadas no Quadro 2 se reportam à oliveira em geral e não a uma variedade em particular. Adverte-se ainda para o facto de que as temperaturas no abrigo (à sombra e a determinada altura do solo) e não na planta são uma aproximação grosseira uma vez que o aumento da temperatura resultante da incidência direta do Sol é muito importante.

A adequação das condições térmicas diárias dos climas locais da região de Alvega à olivicultura (Fig. 6) é aferida com recurso à metodologia proposta por Jaraquemada (1977). Salienta-se ainda que o gráfico proposto e empregue neste estudo representa a temperatura correspondente ao mês seguinte à maturação do fruto pela influência que esta tem no rendimento em azeite (Fig. 6). A região de Alvega oferece condições térmicas diárias favoráveis à olivicultura apresentando os climas locais temperaturas médias, essencialmente, carácter sem prejuízo a ótimo ao longo do ciclo biológico anual da oliveira (Fig. 6). Não obstante o disposto, as plantas cultivadas vivem a realidade meteorológica diária e não a abstração representada pelos valores médios da climatologia (Jaraquemada, 1977). 


\begin{tabular}{|c|c|c|c|c|c|c|c|}
\hline $\begin{array}{l}\text { Unidades } \\
\text { de Relevo }\end{array}$ & $\begin{array}{l}\text { Estação } \\
\text { Meteorológica }\end{array}$ & $\begin{array}{l}\text { Altitude } \\
\text { (metros) }\end{array}$ & Abrolhamento & Inflorescências & Floração & Fecundação & Maturação \\
\hline Planalto & S. Facundo & 209 & 2 de Fevereiro & 2 de Abril & 11 de Maio & 14 de Junho & 1 de Dezembro \\
\hline $\begin{array}{l}\text { Vertentes } \\
\text { Expostas } \\
\text { a Norte }\end{array}$ & - & - & \multicolumn{5}{|c|}{$\begin{array}{l}\text { As datas médias de início deverão registar um ligeiro atraso relativamente aos } \\
\text { restantes climas locais }\end{array}$} \\
\hline $\begin{array}{l}\text { Vertentes } \\
\text { Expostas } \\
\text { a Sul }\end{array}$ & - & - & \multicolumn{5}{|c|}{$\begin{array}{l}\text { As datas médias de início deverão registar uma ligeira precocidade relativamente } \\
\text { aos restantes climas locais à exceção dos climas locais das vertentes expostas a } \\
\text { Oeste }\end{array}$} \\
\hline $\begin{array}{l}\text { Vertentes } \\
\text { Expostas } \\
\text { a Oeste }\end{array}$ & - & - & \multicolumn{5}{|c|}{$\begin{array}{l}\text { As datas médias de início deverão registar uma ligeira precocidade relativamente } \\
\text { aos restantes climas locais }\end{array}$} \\
\hline $\begin{array}{l}\text { Fundos de } \\
\text { Vale }\end{array}$ & - & - & \multicolumn{5}{|c|}{$\begin{array}{l}\text { As datas médias de início deverão registar uma ligeira precocidade relativamente } \\
\text { aos restantes climas locais à exceção dos climas locais das vertentes expostas a Sul e } \\
\text { a Oeste }\end{array}$} \\
\hline
\end{tabular}

Quadro 2 - Datas médias de início das fases fenológicas da oliveira nos climas locais da região de Alvega (Fonte dos dados: rede meteorológica da PEGOP, SA).

Os requisitos de frio da oliveira explicam a abstinência de floração em áreas com Invernos amenos tornando-as inaptas para a olivicultura (Melo-Abreu et al., 2004). Adverte-se que uma incompleta acumulação de frio atrasa o fim da vernalização e o início da floração além de dilatar o período de floração (Barranco et al., 1994, In MeloAbreu et al., 2004). O desenvolvimento morfológico dos botões florais segue o tratamento das baixas temperaturas, que os habilita a crescerem sob temperaturas altas (Hackett e Hartmann, 1964, In Melo-Abreu et al., 2004). Avalia-se a adaptabilidade local da olivicultura na região de Alvega através da modelação das datas médias de início da floração da oliveira com base na 'acumulação de frio' e no 'tempo térmico'. Para o efeito, recorre-se a um modelo frio-calor resultante da generalização e simplificação do modelo Utah (Melo-Abreu et al., 2004). Este modelo pressupõe a existência de dois 
processos encadeados: um relacionado com o terminus da vernalização, o qual depende da 'acumulação de frio' e, outro, na fase subsequente de desenvolvimento que depende da acumulação de 'tempo térmico' acima da temperatura-base. O erro médio quadrático (RMSE) das datas médias de início da floração previstas é neste modelo calculado pelo algoritmo através do método Downhill Simplex (Nelder e Mead, 1965, In Melo- Abreu et al., 2004). Nesta modelação, as temperaturas máximas e mínimas diárias do ar são introduzidas no modelo, enquanto temperaturas horárias são geradas a partir daquele, usando o modelo de De Witt et al. (1978, In Melo-Abreu et al., 2004) que se tem mostrado adequado às condições mediterrâneas (Melo-Abreu e Campbell, 1996, In Melo-Abreu et al., 2004). A acumulação de frio começa a 1 de Outubro e todos os valores negativos desta acumulação são descartados. Após suficiente acumulação de frio, inicia-se a acumulação de 'tempo térmico'. O modelo foi calibrado com recurso aos valores dos parâmetros definidos (Quadro 3).

\begin{tabular}{|c|c|c|c|c|c|c|c|}
\hline Espécie & $\mathbf{T}_{\mathbf{o}}\left({ }^{\circ} \mathbf{C}\right)$ & $\mathbf{T}_{\mathbf{x}}\left({ }^{\circ} \mathbf{C}\right)$ & $\mathbf{a}(\mathbf{U})$ & $\mathbf{T U}(\mathbf{U})$ & $\mathbf{T}_{\mathbf{b}}\left({ }^{\circ} \mathbf{C}\right)$ & $\mathbf{T T}\left({ }^{\circ} \mathbf{C}\right.$ dias $)$ & RMSE (dias) \\
\hline Olea europaea L. & 7.3 & 20.7 & -0.56 & $494^{*}$ & 9.1 & $510^{*}$ & 2.9 \\
\hline
\end{tabular}

Quadro 3 - Valores dos parâmetros para a oliveira (Olea europaea L.) definidos por Melo-Abreu et al. (2004) para a calibração do modelo de previsão das datas de floração. *valores referentes

à variedade Hojiblanca por ser, das variedades empregues, aquela que apresenta maiores necessidades de frio e de calor. TU - total de unidades de frio até ao fim da vernalização; TT $\left({ }^{\circ} \mathrm{C}\right.$ Dias) - tempo térmico desde o fim da vernalização até à plena floração; RMSE (Dias) - erro médio quadrático das datas previstas de floração.

A forte adaptabilidade local da oliveira na região de Alvega é atestada pelos resultados da modelação das datas médias de início da floração, pois esta fase fenológica ocorre em todos os locais da região de Alvega e, na Primavera (Quadro 4), tal como na maioria das áreas olivícolas (Melo-Abreu et al., 2004).

\begin{tabular}{|c|c|c|c|}
\hline \multirow{2}{*}{ Espécie } & Localização & $\begin{array}{c}\text { Data Média de Início da Floração } \\
\text { (Número de Ordem do Ano) }\end{array}$ & $\begin{array}{c}\text { Data Média de Início da Floração } \\
\text { (Dia de Maio) }\end{array}$ \\
\hline \multirow{3}{*}{ Olea europaea L. } & Planalto (S. Facundo) & 132 & 12 \\
\cline { 2 - 4 } & Topos de Interflúvio (Gavião) & 139 & 19 \\
\cline { 2 - 4 } & Terraço Fluvial (CTP) & 136 & 16 \\
\cline { 2 - 4 } & Terraço Fluvial (Pego) & 135 & 16 \\
\hline
\end{tabular}

Quadro 4 - Datas médias de início da floração da oliveira (Olea europaea L.) nos diversos locais da região de Alvega (Fonte dos dados: rede meteorológica da PEGOP, SA). 
Rede Meteorológica da PEGOP, SA Estaçăo Meteorológica da Central Termoeléctrica do Pego
Latitude: $39^{\circ} 27^{\prime} 42^{\prime \prime} \mathrm{N}$ Longitude: $8^{\circ} 06^{\prime} 44^{\prime \prime} \mathrm{W}$ Altitude: $109,763 \mathrm{~m}$

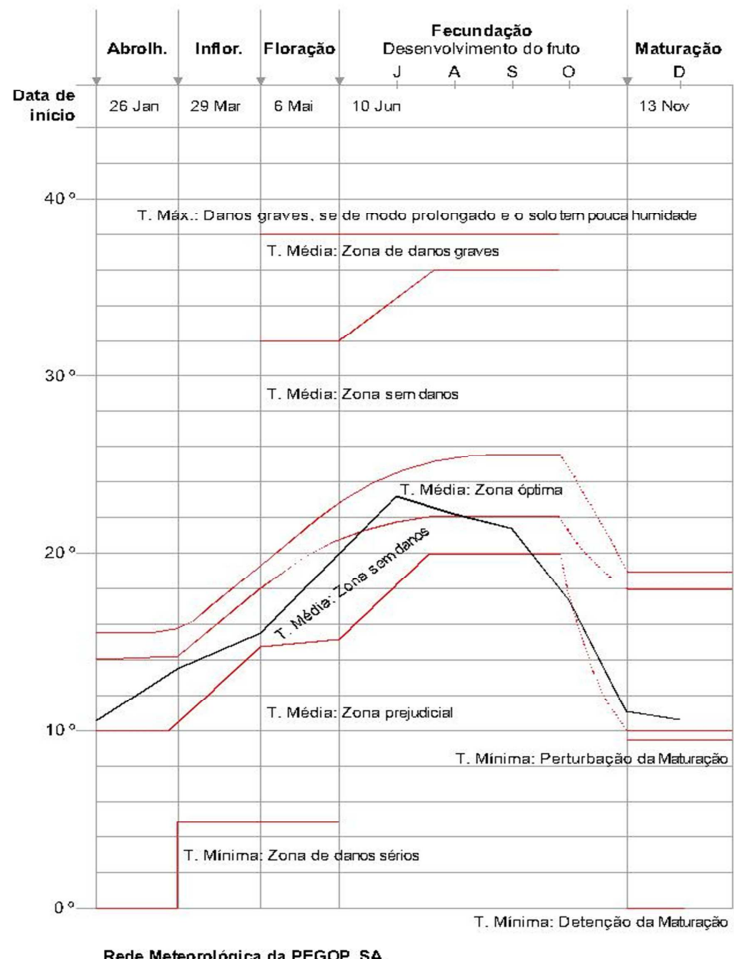

Estaçăo Meteorológica do Pego
Latitude: $39^{\circ} 27^{\prime} 18^{\prime \prime}$ N Longitude: $8^{\circ} 08^{\prime} 29^{\prime \prime}$ W Altitude: $93 \mathrm{~m}$

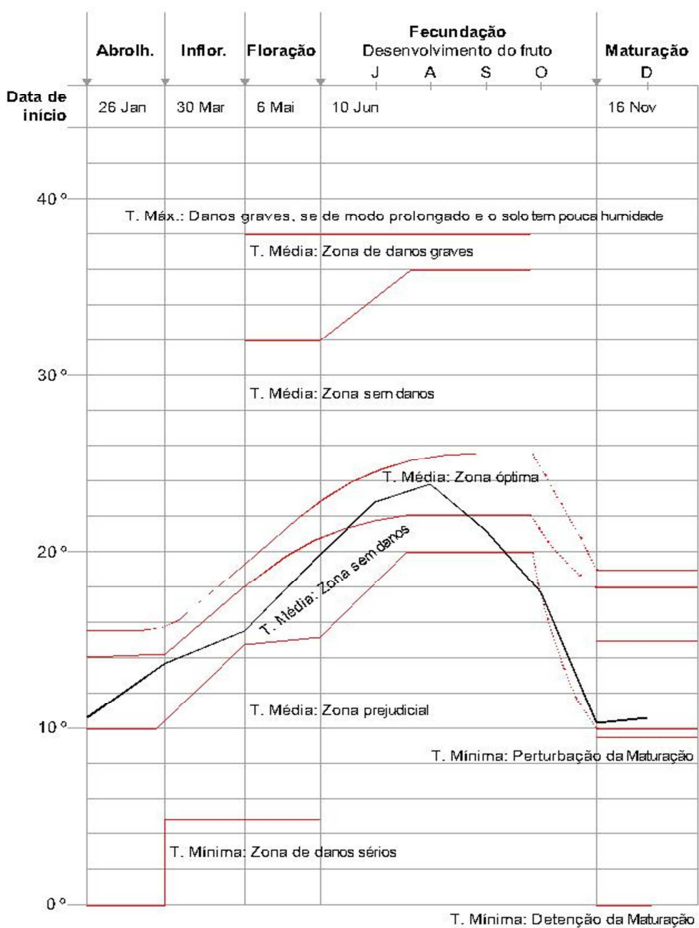

Rede Meteorológica da PEGOP, SA Estaçăo Meteorológica de Gaviăo
Latitude: $39^{\circ} 27^{\prime} 46^{\prime \prime}$ N Longitude: $7^{\circ} 56^{\prime} 24^{\prime \prime}$ W Altitude: $280 \mathrm{~m}$

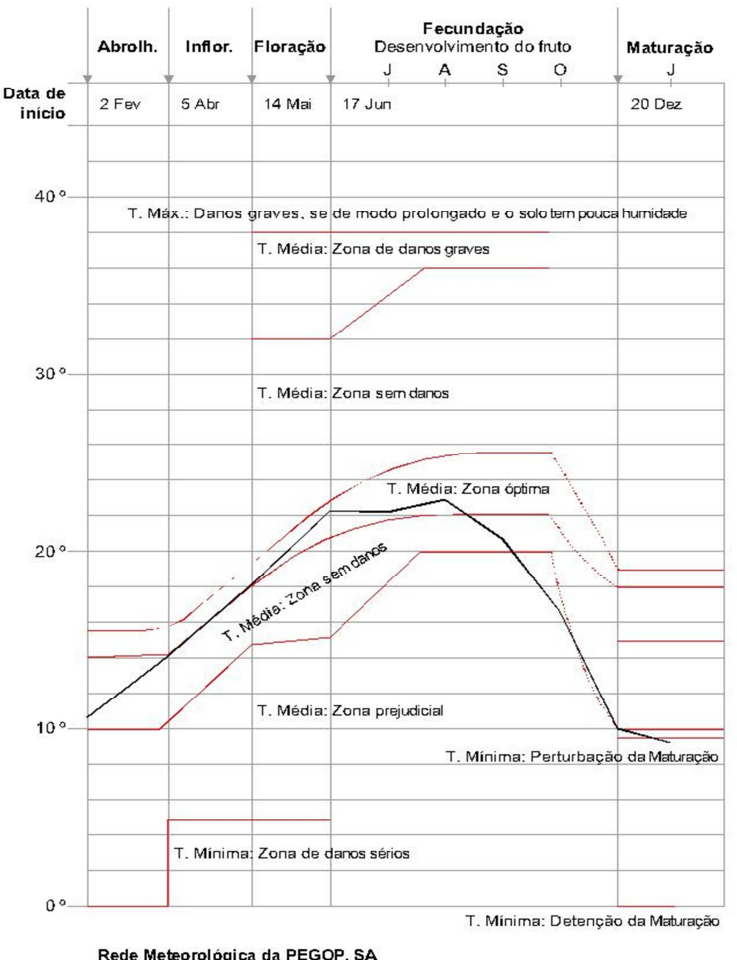

Estaçăo Meteorológica de S. Facundo
Latitude: $39^{\circ} 22^{\prime} 27^{\prime \prime}$ N Longitude: $8^{\circ} 05^{\prime} 54^{\prime \prime W}$ Altitude: $209 \mathrm{~m}$

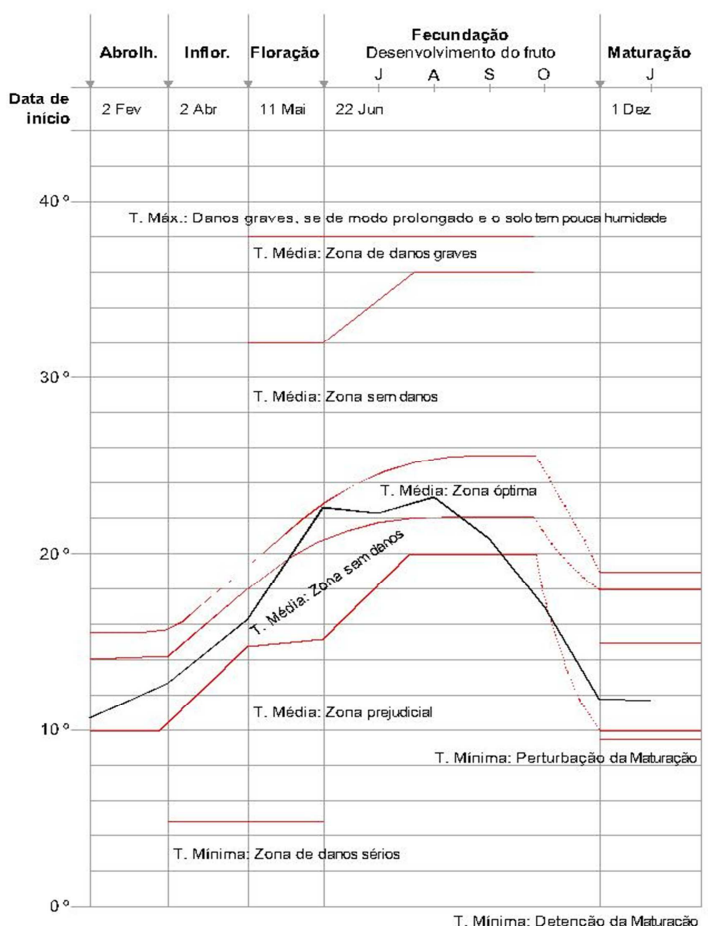

Fig. 6 - Exigências térmicas da oliveira na região de Alvega (Adaptado de Jaraquemada, 1977) (Fonte dos dados: rede meteorológica da PEGOP, SA). 


\section{b) Temperatura Mínima e Perigo de Geada}

Distinguem-se três tipos de geadas em função das origens da sua formação nomeadamente de irradiação (em sentido restrito), de advecção-radiação e de advecção-evaporação (Melo-Abreu et al., 2000). Debruçamo-nos, em particular, sobre as geadas de irradiação em sentido restrito, por serem aquelas que dependem fortemente de fatores geográficos locais e, por serem as mais frequentes em Portugal Continental (Raposo, 1998). As geadas mais graves para as culturas são as geadas tardias de Primavera e as precoces de Outono.

As geadas de irradiação têm origem no balanço energético negativo da superfície terrestre resultante da radiação terrestre efetiva ${ }^{1}$ associada a condições atmosféricas particulares caracterizadas por céu limpo, fraca turbulência (vento fraco ou nulo) e baixa humidade relativa (Oke, 1996). O ar em contacto com as superfícies radiantes arrefece formando uma massa de ar estável e fria junto à superfície terrestre, desenvolvendo-se uma inversão térmica vertical (Oke, 1996). A presença de topografia contrastada favorece a drenagem e acumulação de ar frio em áreas deprimidas em noites de arrefecimento radiativo (Oke, 1996). Assim, em noites anticiclónicas, calmas e sem nebulosidade, as áreas de relevo acidentado apresentam uma divisão térmica vertical estruturada em três zonas: uma zona muito fria no fundo de vale (lago de ar frio), uma zona fria no topo de interflúvio e uma zona menos fria do que as anteriores na vertente designada por cintura térmica (Geiger et al., 2003). Deste modo, a severidade das geadas de irradiação varia consideravelmente com as condições gerais da atmosfera e com os contrastes locais da topografia e uso do solo. Culturas agrícolas situadas em depressões do terreno e áreas próximas dos fundos de vales são afetadas com maior severidade por este fenómeno meteorológico (Melo-Abreu et al., 2000). A ocorrência de temperaturas mínimas baixas e o consequente perigo de formação de geada de irradiação condicionam consideravelmente a prática da olivicultura sendo importante a modelação da sua perigosidade na região de Alvega. Assim, a Carta do Perigo de Geada de Irradiação na Região de Alvega (Fig. 8) foi construída em ambiente SIG através do software ArcGis 9.3 (ESRI). A classificação em áreas de Baixo, Médio e Alto perigo de formação de geada de irradiação (Fig. 8) resulta do conhecimento dos padrões espaciais das temperaturas mínimas diárias do ar (rede meteorológica do Próprio) em diferentes

\footnotetext{
${ }^{1}$ A radiação terrestre efetiva é o balanço da radiação obtido por subtração entre o fluxo de grande comprimento de onda ascendente e descendente (Oke, 1996).
} 
condições atmosféricas, tendo-se verificado a presença de fenómenos de drenagem e acumulação de ar frio em noites de arrefecimento radiativo nos vales da região de Alvega (Correia, 2011). Embora o limiar convencionado para a formação de geada ao nível do solo seja de $4{ }^{\circ} \mathrm{C}$ no abrigo (em situações anticiclónicas) devido a fortes inversões térmicas que se desenvolvem entre o nível do solo e o nível dos instrumentos de medição no abrigo $(1.5 \mathrm{~m})$, considerou-se neste estudo os $0^{\circ} \mathrm{C}$ em abrigo uma vez que, no caso da olivicultura, são mais relevantes as temperaturas ao nível das copas (1.5 m ou mais do solo) do que as temperaturas no espaço dos fustes.

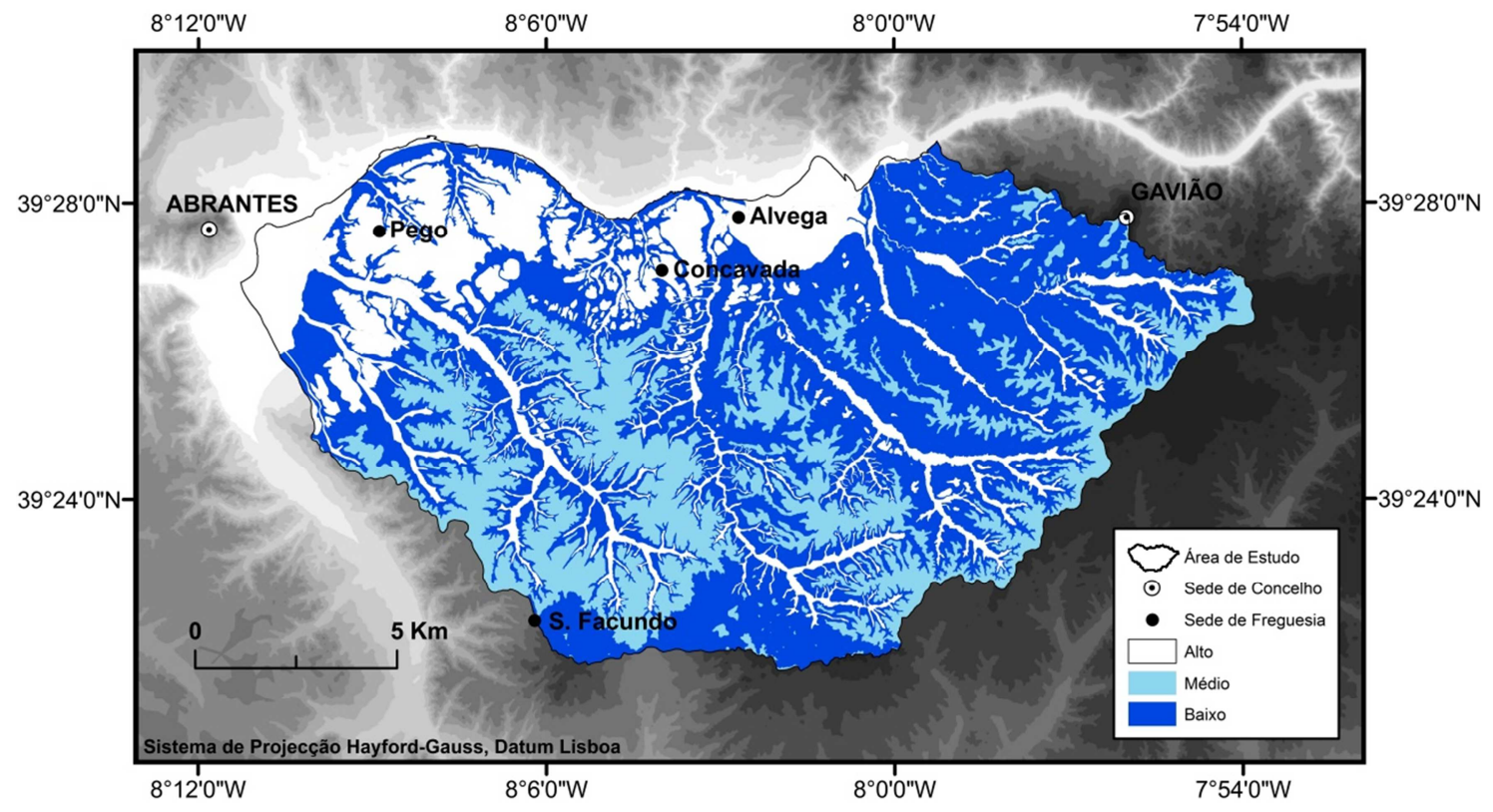

Fig. 8 - Carta do Perigo de Geada de Irradiação na Região de Alvega.

\subsubsection{Precipitação}

A prática da olivicultura em condições de sequeiro apresenta, salvo casos muito particulares, um requisito mínimo de precipitação média anual de 400 a 500 mm, ou seja, 4000 a $5000 \mathrm{~m}^{3}$ de água por ha (García, 2005). Em termos de necessidades de água na oliveira, o período crítico decorre entre a floração e a maturação do fruto coincidindo quase na totalidade com o período de maior escassez de precipitações (García, 2005); esta coincidência cumpre-se em toda a área de estudo (Correia, 2011). Além do referido, existe uma relação entre a precipitação e a produção olivícola sendo referido, por vários autores da especialidade, diferentes limiares inferiores de precipitação para a obtenção 
de boas colheitas: $725 \mathrm{~mm}$, segundo Ortega Nieto; acima dos $750 \mathrm{~mm}$, segundo Faustino de Andrés e E. Roman; entre 600 e 800 mm, segundo Anagostopoulos (In García, 2005). O clima da região de Alvega apresenta uma precipitação média anual de $637.2 \mathrm{~mm}$ (Alvega) que proporciona condições favoráveis à olivicultura. Não obstante o disposto, esta região manifesta contrastes pluviométricos locais que poderão explicar parcialmente diferenças nas colheitas. Deste modo, a precipitação média anual nas áreas de interflúvio varia entre $746.1 \mathrm{~mm}$ no planalto (Margem) e $749.0 \mathrm{~mm}$ nos topos de interflúvio (Gavião), ao passo que a precipitação média anual das áreas deprimidas oscila entre $628.6 \mathrm{~mm}$ nos terraços fluviais (Abrantes - Concavada) e $637.6 \mathrm{~mm}$ nos fundos de vale (Bemposta). Os locais de vertente fazem a transição com valores intermédios de precipitação. Estes valores de precipitação média anual em função da altitude são corroborados pelo Mapa da Precipitação de Portugal para o período de 1931-1960 à escala 1: 500000 (Daveau et al., 1977).

\subsubsection{Vento}

O vento poderá condicionar a prática da olivicultura, por um lado, através de danos provocados por ação mecânica (quebra de ramos e derrube de árvores) e, por outro, através de desidratação da vegetação resultante do efeito combinado com a baixa humidade relativa reforçado pela presença de temperaturas altas.

A morfologia do terreno (vales abertos) não deverá imprimir, à escala local, distorções consideráveis no rumo e na velocidade dos sistemas de ventos da circulação regional. Assim, os efeitos mecânicos do vento, prejudiciais à olivicultura, não deverão ser consideráveis na região de Alvega. Os efeitos do vento, prejudiciais à olivicultura, resultantes da sua combinação com a baixa humidade relativa reforçada pela presença de temperaturas altas deverão apresentar fraca expressão em toda a região, inclusivamente nas áreas deprimidas (fundos de vale e terraços fluviais) uma vez que a morfologia (vales abertos) não propicia, nem a canalização de ventos nem a permanência de temperaturas altas por efeito de abrigo.

Os sistemas de ventos locais de origem térmica, relacionados com os regimes radiativos das vertentes que se possam desenvolver no seio da região de Alvega, nomeadamente

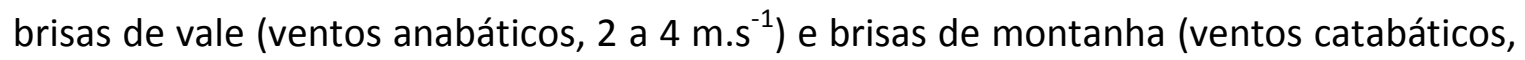


2 a $3 \mathrm{~m} \cdot \mathrm{s}^{-1}$ ) não apresentam velocidades capazes de imprimir danos por ação mecânica à oliveira pelo que não condicionam a prática da olivicultura.

\subsection{Suscetibilidade Local aos Acidentes Agroclimáticos da Olivicultura}

\subsubsection{Excesso de Humidade no Solo e Chuvas Torrenciais}

Na região de Alvega, as áreas que apresentam maior suscetibilidade de inundação, sendo por isso, passíveis de excesso de humidade, são os fundos de vale. Esta circunstância deve-se à convergência das águas de escoamento provenientes da drenagem das áreas sobranceiras adjacentes (planalto e topos de interflúvio) canalizada através da densa rede de barrancos e valeiros desenvolvida ao longo das vertentes. 0 potencial excesso de humidade dos fundos de vale é ainda reforçado pelos seus fracos declives e pela impermeabilidade dos seus solos (aluviões e coluviões).

$\mathrm{Na}$ região de Alvega, as áreas de vertente apresentam maior suscetibilidade a fenómenos de erosão hídrica relativamente às restantes devido aos declives acentuados. Em termos de chuvas abundantes, causa indispensável à ocorrência deste tipo de fenómenos, refere-se que a frequência média de trovoadas em Alvega é de 22 dias/ano ocorrendo principalmente nos meses de Abril, Maio, Junho, Setembro e Outubro. Embora estes valores não sejam elevados, são inadequados para permitirem conclusões rigorosas, pois nada referem sobre os quantitativos. Os resultados da análise estatística dos valores máximos no ano da quantidade diária de precipitação em Portugal Continental para a estação meteorológica de Alvega e posto udométrico de Gavião referem valores elevados quer para curtos $\left(M_{5}\right)$ quer para longos $\left(M_{100}\right)$ períodos de retorno atestando a existência de precipitações intensas nesta região (Quadro 5).

Refira-se ainda que as áreas topograficamente mais elevadas registam valores superiores às áreas deprimidas quer para curtos $\left(M_{5}\right)$ quer para longos $\left(M_{100}\right)$ períodos de retorno (Quadro 5) atestando uma subida de intensidade das precipitações diárias com a altitude nesta região. 


\begin{tabular}{|c|c|c|}
\hline Propriedades e & Estação Meteorológica & Posto Udométrico \\
\hline Características & Alvega & Gavião \\
\hline Latitude & $39 \circ 28^{\prime} \mathrm{N}$ & $39 \circ 12^{\prime} \mathrm{N}$ \\
\hline Longitude & $8^{\circ} 03^{\prime} \mathrm{W}$ & $7058^{\prime} \mathrm{W}$ \\
\hline Altitude & $51 \mathrm{~m}$ & $281 \mathrm{~m}$ \\
\hline Período & $1942-1974$ & $1932-1974$ \\
\hline$M_{5}$ & $54.8 \mathrm{~mm}$ & $70.9 \mathrm{~mm}$ \\
\hline$M_{10}$ & $63.6 \mathrm{~mm}$ & $83.3 \mathrm{~mm}$ \\
\hline $\mathbf{M}_{25}$ & $74.6 \mathrm{~mm}$ & $98.9 \mathrm{~mm}$ \\
\hline$M_{50}$ & $82.8 \mathrm{~mm}$ & $110.5 \mathrm{~mm}$ \\
\hline$M_{100}$ & $91.0 \mathrm{~mm}$ & $122.0 \mathrm{~mm}$ \\
\hline
\end{tabular}

\subsubsection{Geadas, Neve e Granizo}

Em Alvega, a frequência média de geadas, potenciadoras de prejuízos à oliveira, é de 34 dias/ano ocorrendo nos meses de Outubro a Maio. No que concerne à suscetibilidade de ocorrência de geadas e dos prejuízos à olivicultura a estas inerentes na região de Alvega remete-se para o ponto $2.2 .2 \mathrm{~b}$ ).

No intuito de compreender a suscetibilidade à queda de neve, potenciadora de prejuízos à oliveira, refere-se que em Alvega, a frequência média de queda de neve e de solo coberto de neve é de 0.16 dias por ano e de 0.06 dias por ano, respetivamente. Deste modo, Alvega apresenta uma fraca suscetibilidade à ocorrência de neve embora a frequência de ocorrência de temperaturas inferiores a $0{ }^{\circ} \mathrm{C}$ seja considerável de Novembro a Março e, inclusive elevada, de Dezembro a Fevereiro. (...)

Para se compreender a suscetibilidade à queda de granizo, potenciadora de prejuízos à oliveira, refere-se que a frequência média de queda de granizo e saraiva é de 1.75 dias por ano em Alvega. Embora esta região apresente uma fraca suscetibilidade à queda de granizo e saraiva refere-se que, a ter lugar, deverá ser nos meses de Janeiro a Maio, sobretudo de Fevereiro a Abril. 


\subsubsection{Vento}

A região de Alvega manifesta uma reduzida suscetibilidade a danos provocados por ação mecânica do vento sobre a oliveira. Isto porque, a velocidade média do vento manifesta valores reduzidos nas áreas deprimidas (terraços fluviais: 3.3 a 3.9 m.s $\mathrm{s}^{-1}$ - rede meteorológica da PEGOP, SA) e inclusive nas áreas sobranceiras de interflúvio (planalto: $4.2 \mathrm{~m} . \mathrm{s}^{-1}$ e topos de interflúvio: $3.8 \mathrm{~m} . \mathrm{s}^{-1}$ - rede meteorológica da PEGOP, SA) onde o efeito de atrito é menor. Embora a velocidade média do vento não seja elevada na região de Alvega, ocorrem, por vezes rajadas fortes que chegam a atingir 11.2 a 13.4 $\mathrm{m} . \mathrm{s}^{-1}$ (rede meteorológica da PEGOP, SA) nas áreas sobranceiras (planaltos e topos de interflúvio) e $25.2 \mathrm{~m} . \mathrm{s}^{-1}$ (rede meteorológica da PEGOP, SA) nas áreas deprimidas (terraços fluviais). Os valores das rajadas máximas mais elevados nas áreas deprimidas (terraços fluviais) comparativamente às áreas sobranceiras (planalto e topos de interflúvio) sugerem a presença de ventos canalizados (Efeito de Venturi) nos vales da região de Alvega. Assim, as áreas deprimidas (fundos de vale e terraços fluviais) apresentam maior suscetibilidade a este tipo de acidente agroclimatológico em situações de ventos canalizados com particular enfâse nos casos em que o rumo do vento coincide com a orientação dos vales.

Também a suscetibilidade a danos inerentes à desidratação da vegetação resultante do efeito combinado do vento com a baixa humidade relativa reforçado pelas temperaturas elevadas deverá ser reduzida na região de Alvega. Porém, situações de canalização de vento (Efeito de Venturi) e de efeito de abrigo poderão aumentar pontualmente a suscetibilidade das áreas deprimidas (fundos de vale e terraços fluviais) a este tipo de acidente agroclimatológico.

\subsubsection{Insolação}

Para se compreender a suscetibilidade à forte insolação, potenciadora de prejuízos à oliveira na região de Alvega, refere-se que o planalto, topos de interflúvio e terraços fluviais manifestam uma elevada insolação, os fundos de vale apresentam uma insolação média e as vertentes (com destaque para as áreas de barrancos e valeiros) uma baixa insolação (Fig. 5). Os meses de maior insolação são Julho e Agosto, assim sendo, será este o período de maior suscetibilidade de ocorrência de danos à oliveira. 


\subsubsection{Temperaturas Altas}

As áreas da região de Alvega com maior suscetibilidade ao efeito das altas temperaturas, passíveis de prejuízos oriundos da intensa desidratação da vegetação, são os fundos de vale e terraços fluviais. Esta circunstância deve-se às temperaturas elevadas resultantes do efeito de abrigo. No intuito de compreender a suscetibilidade às temperaturas altas, potenciadoras de prejuízos à olivicultura, refere-se que a frequência média de temperaturas máximas superiores a $35^{\circ} \mathrm{C}$ em Alvega é de 17 dias por ano ocorrendo principalmente nos meses de Junho, Julho, Agosto e Setembro.

\section{Resultados}

\subsection{Aptidão e Constrangimentos Agroclimáticos Locais à Olivicultura}

\subsubsection{Com Aptidão: Planalto e Topos de Interflúvio}

O ambiente agroclimático do planalto e dos topos de interflúvio proporciona uma elevada aptidão olivícola (Fig. 9). A forte insolação favorece a produção de assimilados nas axilas das folhas contribuindo diretamente para a formação de flores e consequentemente para a produção de azeitona, além de beneficiar o processo fotossintético; os elevados valores de radiação solar favorecem o aumento da concentração do fruto em óleo na fase de maturação; as temperaturas proporcionam o desenvolvimento das diversas fases fenológicas do ciclo biológico anual da oliveira em condições não prejudiciais a ótimas; os quantitativos anuais de precipitação satisfazem as necessidades hídricas da oliveira proporcionando inclusive a obtenção de boas produções. A fraca suscetibilidade destas áreas aos acidentes agroclimáticos também justifica a elevada aptidão olivícola.

\subsubsection{Sem Aptidão: Fundos de Vale e Vertentes}

Embora algumas condições agroclimáticas se afigurem favoráveis à olivicultura nos fundos de vale (elevados valores de radiação solar, as temperaturas favoráveis ao desenvolvimento das diversas fases fenológicas do ciclo biológico anual da oliveira em condições não prejudiciais a ótimas, a moderada insolação e os valores de precipitação capazes de satisfazer as necessidades hídricas da oliveira e de obter boas produções), estes apresentam-se desprovidos de aptidão olivícola. Tal facto deve-se a características 
como o elevado perigo de formação de geada de irradiação, ainda que de fraca severidade na época de abrolhamento (geadas tardias) e na época de maturação do fruto (geadas precoces), são potenciadoras de importantes reduções na quantidade e qualidade da produção oleica; por outro lado, a existência de áreas planas em posição deprimida com um elevado nível freático, compostas, essencialmente, por aluviões e coluviões capazes de proporcionar situações de excesso de humidade a que a oliveira é muito sensível.

A ambiência agroclimática que caracteriza as vertentes da região de Alvega também revela falta de aptidão olivícola (Fig. 9). Embora os moderados a elevados valores de radiação solar, as temperaturas favoráveis ao desenvolvimento das diversas fases fenológicas do ciclo biológico anual da oliveira em condições não prejudiciais a ótimas, os quantitativos anuais de precipitação acrescidos de uma fraca suscetibilidade a acidentes agroclimáticos possam indiciar aptidão olivícola, a fraca insolação inviabiliza a olivicultura nestas áreas (Fig. 9).

\subsubsection{Com Aptidão Condicionada: Terraços Fluviais}

Os terraços fluviais da região de Alvega revelam aptidão olivícola, ainda que de forma condicionada (Fig. 9). As suas potencialidades agroclimáticas baseiam-se nos elevados valores de radiação solar, nas temperaturas favoráveis ao desenvolvimento das diversas fases fenológicas do ciclo biológico anual da oliveira em condições não prejudiciais a ótimas, na forte insolação, nos quantitativos de precipitação aptos à satisfação das necessidades hídricas da oliveira e inclusive à obtenção de boas produções. Porém, o elevado perigo de formação de geada de irradiação, ainda que de fraca severidade na época de abrolhamento (geadas tardias) e na época da maturação do fruto (geadas precoces), constitui um constrangimento agroclimático à olivicultura nos terraços fluviais. Tendo em conta a intensidade das baixas temperaturas (Correia, 2011), esta condicionante poderá ser ultrapassada através da seleção de variedades pouco sensíveis ao frio.

\subsection{Carta das Potencialidades Agroclimáticas Locais à Olivicultura}

As potencialidades olivícolas são caracterizadas com base na aptidão e nos constrangimentos agroclimáticos locais existentes na região de Alvega. A Carta das 
Potencialidades Agroclimáticas Locais à Olivicultura na Região de Alvega elaborada em ambiente SIG (software ArcGis 9.3, ESRI) ilustra o modo como os climas locais desta região satisfazem os requisitos climáticos da olivicultura (Fig. 9). O modo como tal se processa encontra-se explicado na legenda do mapa da Figura 9. Além disso, observações de campo permitiram validar algumas destas potencialidades agroclimáticas locais à olivicultura. De modo a facilitar a compreensão das potencialidades agroclimáticas locais da olivicultura utiliza-se uma classificação simples com dois níveis de informação. Assim, a aptidão agroclimática local à olivicultura é classificada em Com Aptidão, Sem Aptidão e Com Aptidão Condicionada com recurso à cor. A esta, sobrepõe-se a tipologia de constrangimentos agroclimáticos indicada com recurso a tramas. Assim, a Carta das Potencialidades Agroclimáticas Locais à Olivicultura na Região de Alvega inclui, além da aptidão, informação relativa ao tipo de constrangimento. A diversidade de climas locais presente na região de Alvega em confronto com os requisitos climáticos da oliveira revela um complexo mosaico de potencialidades agroclimáticas locais à olivicultura (Fig. 9).

\section{Discussão e Conclusões}

O cultivo da oliveira para fins comerciais apresenta como principal objetivo a rentabilidade económica. Uma vez que a implantação de olival constituí um investimento a longo prazo torna-se pertinente “(...) realizar los estúdios previos necesarios para conocer aspectos de la variedad a emplear, el solo y el clima que pueden condicionar la rentabilidad de la plantación" (Barranco et al., 2008). Neste sentido, estudos de climatologia à escala local podem dar resposta às necessidades da agricultura de conhecer as características climáticas da camada de ar junto ao solo assim como a sua variabilidade espacial. Refira-se que historicamente a climatologia local foi desenvolvida "(...) in response to increasing demand for agricultural production through agroclimatological knowledge" (Yoshino, 1997).

O ensaio aqui desenvolvido pretendeu testar uma metodologia de avaliação do potencial agroclimático local para a instalação de culturas agrícolas. Para o efeito, selecionou-se a olivicultura como cultura agrícola a instalar e a região de Alvega como área de estudo. 
As potencialidades olivícolas na região de Alvega foram definidas com base nas características e distribuição da aptidão e dos constrangimentos agroclimáticos. Deste modo, construiu-se uma carta a partir do tratamento de informação resultante do estudo das condições agroclimáticas favoráveis ou limitantes e da suscetibilidade aos acidentes agroclimáticos da olivicultura na região de Alvega em ambiente SIG, que permitiu a definição de unidades com potenciais agroclimáticos locais homogéneos. Os elementos climáticos condicionantes da olivicultura constituem elementos-chave na definição da aptidão e dos constrangimentos com tradução no potencial agroclimático local. Foram assim delimitados três tipos de aptidão agroclimática, caracterizados com base no grau de satisfação dos requisitos climáticos da oliveira por parte dos climas locais. As áreas desprovidas de aptidão agroclimática ou com aptidão agroclimática condicionada foram ainda caracterizadas com base na tipologia de constrangimentos agroclimáticos presentes.

A carta das potencialidades agroclimáticas locais à olivicultura na região de Alvega revela o complexo mosaico de aptidões e constrangimentos agroclimáticos e a sua importância espacial. Além do excesso de humidade nos fundos de vale, da presença de lagos de ar frio nos fundos de vale e nos terraços fluviais, nota-se uma clara assimetria espacial ao nível da insolação com as vertentes a apresentarem valores particularmente baixos em consequência da presença de inúmeros valeiros e barrancos oriundos da intensa erosão fluvial. Os referidos contrastes climáticos são muito interessantes e têm reflexos na distribuição do potencial agroclimático da olivicultura na região de Alvega.

A carta das potencialidades agroclimáticas locais, neste caso, da olivicultura na região de Alvega, demonstra a pertinência e exequibilidade da metodologia de avaliação do potencial agroclimático para a instalação de culturas agrícolas testada no presente ensaio a aplicar noutras culturas e regiões. Adverte-se para o facto de esta metodologia constituir uma proposta inicial que naturalmente poderá ser aperfeiçoada no futuro. Cartas das potencialidades agroclimáticas locais para a instalação de culturas agrícolas acompanhadas de breves caracterizações constituem aplicações dos conhecimentos climáticos locais à agricultura. Assim, orientações climáticas para a agricultura como as que aqui se propõem dirigidas aos agentes de planeamento e/ou ordenamento do território mas também ao público em geral demonstram a aplicabilidade desta metodologia e divulgam a potencial contribuição da climatologia local para o ordenamento, planeamento e gestão agrícola do território. 
POTENCIALIDADES AGROCLIMÁTICAS LOCAIS À OLIVICULTURA NA REGIÃO DE ALVEGA

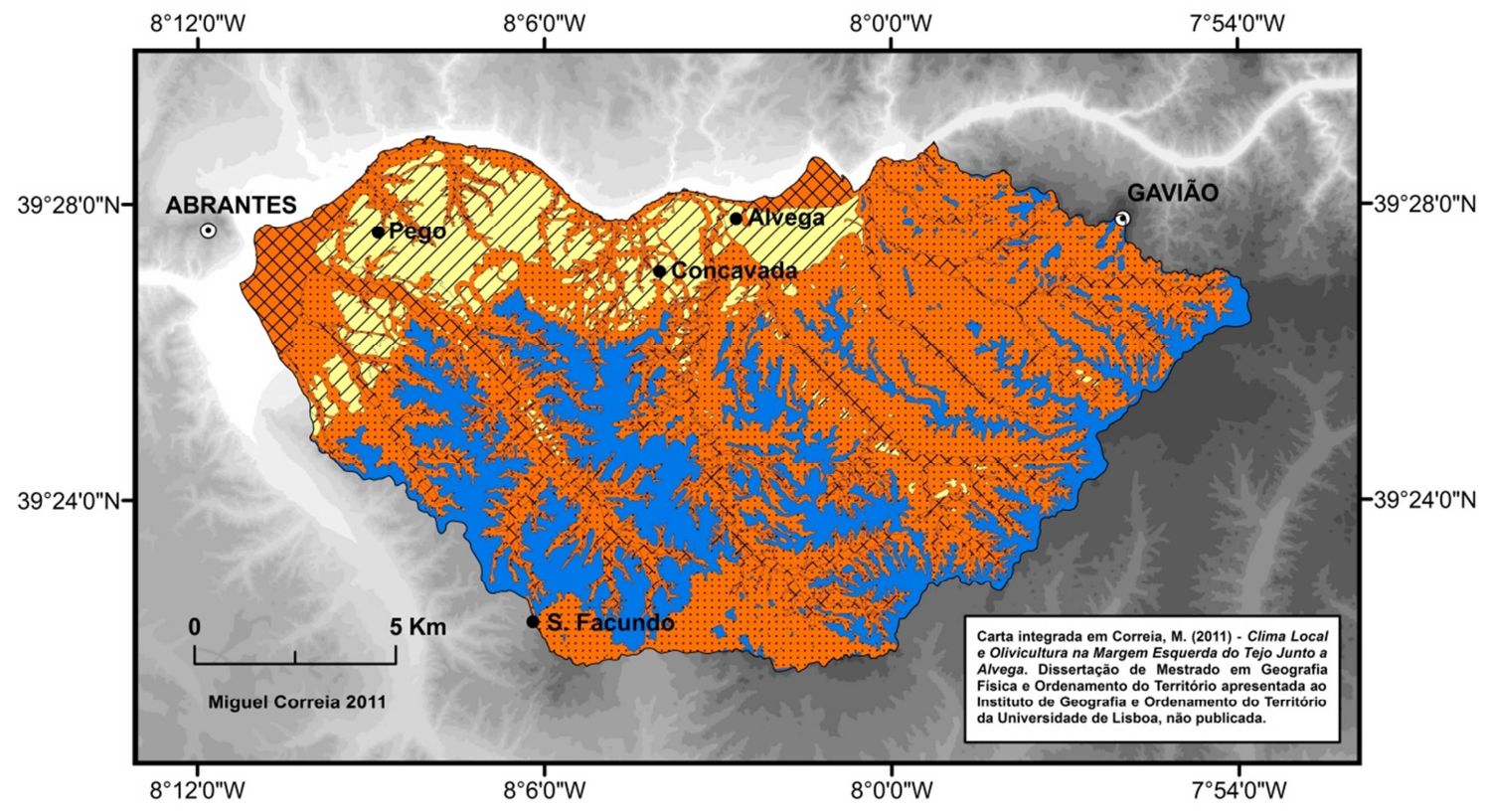

\section{CONSTRANGIMENTOS AGROCLIMÁTICOS LOCAIS à OLIVICULTURA}

\begin{tabular}{|c|c|}
\hline Constrangimentos Agroclimáticos Locais à Olivicultura \\
\hline Lagos de Ar Frio \\
\hline Excesso de Humidade \\
\hline Fraca Insolação & $: \vdots: \vdots: \vdots: \vdots \vdots$ \\
\hline
\end{tabular}

APTIDÃO AGROCLIMÁTICA LOCAL DA OLIVICULTURA

\begin{tabular}{|c|c|}
\hline \multicolumn{2}{|c|}{ Aptidão Agroclimática Local à Olivicultura } \\
\hline Com Aptidão & \\
\hline Com Aptidão Condicionada & \\
\hline Sem Aptidão & \\
\hline
\end{tabular}




\section{POTENCIALIDADES AGROCLIMÁTICAS LOCAIS À OLIVICULTURA}

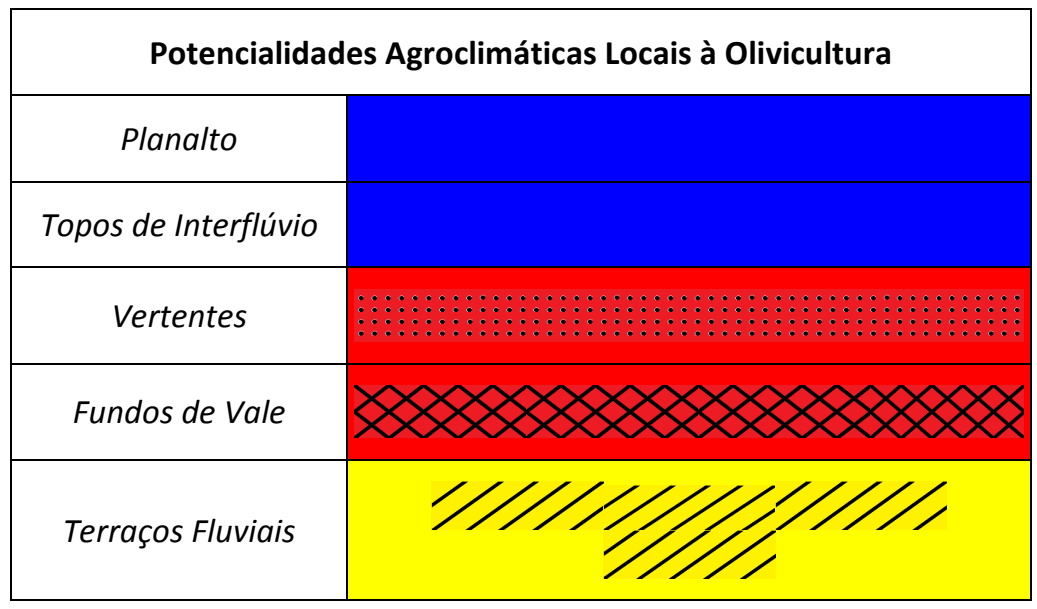

Fig. 9 - Carta das Potencialidades Agroclimáticas Locais à Olivicultura na Região de Alvega.

Sistema de Projeção Hayford-Gauss, Datum Lisboa. Base Topográfica: Carta Militar de Portugal 1: 25 000, Folhas 321, 322, 323, 331, 332, 333, 343, 344, 345, Instituto Geográfico do Exército (Formato Digital).

\section{Referências}

Alcoforado, M. J., Andrade, E., Neves, M., Vieira, G. (1993). "Climas Locais da Arrábida no Inverno" Finisterra - Revista Portuguesa de Geografia 28: 55-56

Barranco, D., Fernández-Escobar, R., Rallo, L. (2008). El Cultivo del Olivo. Madrid, Mundi-Prensa (Ed.), 845 p.

Barry, R. G. (1994). "Past and Potential Future Changes in Mountain Environments: a Review" Mountain Environments in Changing Climates: 3-35

Böhm, J. (2013). O Grande Livro da Oliveira e do Azeite. Portugal Oleícola. Lisboa, Dinalivro (Ed.), 288 p.

Correia, M. F. (2011). Clima Local e Aptidão Olivícola. A Margem Esquerda do Tejo Junto a Alvega. Mestrado, Universidade de Lisboa.

Daveau, S., Coelho, C., V., C., Carvalho, L. (1977). Répartition et Rythme des Precipitations au Portugal. Lisboa, Centro de Estudos Geográficos (Ed.), 192 p.

Feio, M. (1991). Clima e Agricultura - Exigências Climáticas das Principais Culturas e Potencialidades Agrícolas do Nosso Clima. Lisboa, Direç̧ão-Geral de Planeamento e Agricultura (Ed.), 266 p.

García, A. G. (2005). Cultivo Moderno do Olival. Mem Martins, Europa-América (Ed.), 296 p.

Garratt, J. R. (1994). The Atmospheric Boundary Layer. Cambridge, Cambridge University Press, 316 p.

Geiger, R., Aron, R. H., Todhunter, P. (2003). The Climate Near the Ground. Lanham, Rowman \& Litlefield Publishers, $584 \mathrm{p}$.

Jaraquemada, A. G. (1977). Contribucion al Estudio de la Fenologia del Olivo en Andalucia. Madrid, Instituto Nacional de Meteorologia, Servicio Meteorológico Nacional (Ed.), Publicatión A-72, 79 p.

Melo-Abreu, J. P., Ribeiro, A. C., Monteiro, A. M. (2000). Proteção das Culturas Contra as Geadas. Mirandela, Direção Regional de Agricultura de Trás-os-Montes (Ed.), 7 p. 
Melo-Abreu, Barranco, D., Cordeiro, A. M., Tous, J., Rogado, B. M., Villalobos, F. J. (2004). “Modelling Olive Flowering Date Using Chilling for Dormancy Release and Thermal Time" Agricultural and Forest Meteorology 125: 117-127

Mora. C. (1998). Aspetos do Clima Local da Arrábida. Mestrado, Universidade de Lisboa.

Mora. C. (2006). Climas da Serra da Estrela. Características Regionais e Particularidades Locais dos Planaltos e do Alto Vale do Zêzere. Doutoramento, Universidade de Lisboa.

Oke, T. R. (1996). Boundary Layer Climates. London, Routledge (Ed.), 464 p.

Patrão, J. D. H. (2003). Gavião: Memórias de um Concelho. Lisboa, Colibri e Câmara Municipal de Gavião (Eds), $455 \mathrm{p}$.

Raposo, J. R. (1998). As Geadas - Suas Causas e Seus Efeitos; Como se Evitam e Como se Combatem. Lisboa, Instituto de Promoção Ambiental (Ed.), 193 p.

Rocha Faria, J. M., Godinho, S., Almeida, M. J., Sousa Machado, M. (1979). O Clima de Portugal (Fascículo XIX) - Análise Estatística dos Valores Máximos do Ano da Quantidade Diária de Precipitação em Portugal. Lisboa, Instituto de Meteorologia e Geofísica (Ed.), 91 p.

Yoshino, M. M. (1997). Agricultural Landuse and Local Climate. Climates and Societies - a Climatological Perspective. Springer (Ed.). Netherlands, The Geojournal Library 36: 381-400 


\section{ANEXOS}

\begin{tabular}{|c|c|c|c|c|c|c|c|}
\hline \multirow{2}{*}{ Estação/Posto } & \multirow{2}{*}{ Propriedade } & \multirow{2}{*}{ Tipo } & \multicolumn{2}{|c|}{ Coordenadas Geográficas } & \multirow{2}{*}{$\begin{array}{l}\text { Altitude } \\
\text { (metros) }\end{array}$} & \multirow{2}{*}{$\begin{array}{c}\text { Posição } \\
\text { Topográfica }\end{array}$} & \multirow{2}{*}{ Período } \\
\hline & & & Latitude & Longitude & & & \\
\hline Alvega (A) & IPMA, IP & $\begin{array}{c}\text { Estação } \\
\text { Meteorológica }\end{array}$ & $39^{\circ} 27^{\prime} 34^{\prime \prime} \mathrm{N}$ & $8^{\circ} 02^{\prime} 33^{\prime \prime} \mathrm{W}$ & 51 & $\begin{array}{l}\text { Terraço } \\
\text { Fluvial }\end{array}$ & $1948-1988$ \\
\hline $\begin{array}{c}\text { Abrantes } \\
\text { (Concavada) } \\
\text { A (C) }\end{array}$ & INAG, IP & $\begin{array}{c}\text { Estação } \\
\text { Meteorológica }\end{array}$ & $39^{\circ} 27^{\prime} 09^{\prime \prime} \mathrm{N}$ & $8^{\circ} 06^{\prime} 03^{\prime \prime} \mathrm{W}$ & 105 & $\begin{array}{l}\text { Terraço } \\
\text { Fluvial }\end{array}$ & $1981-2000$ \\
\hline Bemposta (B) & INAG, IP & $\begin{array}{c}\text { Posto } \\
\text { Udométrico }\end{array}$ & $39^{\circ} 20^{\prime} 50^{\prime \prime} \mathrm{N}$ & $8^{\circ} 08^{\prime} 23^{\prime \prime} \mathrm{W}$ & 96 & $\begin{array}{c}\text { Fundo de } \\
\text { Vale }\end{array}$ & $1981-2000$ \\
\hline Gavião (G) & INAG, IP & $\begin{array}{c}\text { Posto } \\
\text { Udométrico }\end{array}$ & $39^{\circ} 27^{\prime} 43^{\prime \prime} \mathrm{N}$ & $7^{\circ} 56^{\prime} 09^{\prime \prime} \mathrm{W}$ & 273 & $\begin{array}{l}\text { Topo de } \\
\text { Interflúvio }\end{array}$ & $1981-2000$ \\
\hline Margem (M) & INAG, IP & $\begin{array}{c}\text { Posto } \\
\text { Udométrico }\end{array}$ & $39^{\circ} 22^{\prime} 56^{\prime \prime} \mathrm{N}$ & $7^{\circ} 54^{\prime} 02^{\prime \prime} \mathrm{W}$ & 210 & Planalto & $1981-2000$ \\
\hline $\begin{array}{c}\text { Central } \\
\text { Termoelétrica } \\
\text { do Pego (СТР) }\end{array}$ & PEGOP, SA & $\begin{array}{c}\text { Estação } \\
\text { Meteorológica }\end{array}$ & $39^{\circ} 27^{\prime} 42^{\prime \prime} \mathrm{N}$ & $8^{\circ} 06^{\prime} 44^{\prime \prime} \mathrm{W}$ & 109.763 & $\begin{array}{l}\text { Terraço } \\
\text { Fluvial }\end{array}$ & $1999-2003$ \\
\hline Gavião (G) & PEGOP, SA & $\begin{array}{c}\text { Estação } \\
\text { Meteorológica }\end{array}$ & $39^{\circ} 27^{\prime} 46^{\prime \prime} \mathrm{N}$ & $7^{\circ} 56^{\prime} 24^{\prime \prime} \mathrm{W}$ & 280 & $\begin{array}{l}\text { Topo de } \\
\text { Interflúvio }\end{array}$ & 1999-2003 \\
\hline Pego (P) & PEGOP, SA & $\begin{array}{c}\text { Estação } \\
\text { Meteorológica }\end{array}$ & $39^{\circ} 27^{\prime} 18^{\prime \prime} \mathrm{N}$ & $8^{\circ} 08^{\prime} 29^{\prime \prime} \mathrm{W}$ & 93 & $\begin{array}{l}\text { Terraço } \\
\text { Fluvial }\end{array}$ & $1999-2003$ \\
\hline S. Facundo (SF) & PEGOP, SA & $\begin{array}{c}\text { Estação } \\
\text { Meteorológica }\end{array}$ & $39^{\circ} 22^{\prime} 27^{\prime \prime} \mathrm{N}$ & $8^{\circ} 05^{\prime} 54^{\prime \prime} \mathrm{W}$ & 209 & Planalto & 1999-2003 \\
\hline $\begin{array}{c}\text { Alto do Termo } \\
\text { (AT) }\end{array}$ & Próprio & $\begin{array}{c}\text { Posto } \\
\text { Termométrico }\end{array}$ & $39^{\circ} 26^{\prime} 59^{\prime \prime} \mathrm{N}$ & $7^{\circ} 59^{\prime} 43^{\prime \prime} \mathrm{W}$ & 172 & $\begin{array}{l}\text { Topo de } \\
\text { Interflúvio }\end{array}$ & $\begin{array}{c}07 / 02 / 10 a \\
27 / 03 / 10\end{array}$ \\
\hline Represa (R) & Próprio & $\begin{array}{c}\text { Posto } \\
\text { Termométrico }\end{array}$ & $39^{\circ} 27^{\prime} 15^{\prime \prime} \mathrm{N}$ & $7^{\circ} 59^{\prime} 12^{\prime \prime} \mathrm{W}$ & 100 & $\begin{array}{c}\text { Fundo de } \\
\text { Vale }\end{array}$ & $\begin{array}{c}07 / 02 / 10 \mathrm{a} \\
27 / 03 / 10\end{array}$ \\
\hline Entrudo (E) & Próprio & $\begin{array}{c}\text { Posto } \\
\text { Termométrico }\end{array}$ & $39^{\circ} 27^{\prime} 37^{\prime \prime} \mathrm{N}$ & $7^{\circ} 58^{\prime} 47^{\prime \prime} \mathrm{W}$ & 213 & $\begin{array}{l}\text { Topo de } \\
\text { Interflúvio }\end{array}$ & $\begin{array}{c}07 / 02 / 10 \text { a } \\
27 / 03 / 10\end{array}$ \\
\hline $\begin{array}{l}\text { Pedregulho } \\
\text { (Pd) }\end{array}$ & Próprio & $\begin{array}{c}\text { Posto } \\
\text { Termométrico }\end{array}$ & $39^{\circ} 24^{\prime} 54^{\prime \prime} \mathrm{N}$ & $8^{\circ} 07^{\prime} 11^{\prime \prime} \mathrm{W}$ & 181 & Planalto & $\begin{array}{c}07 / 02 / 10 \text { a } \\
27 / 03 / 10\end{array}$ \\
\hline Coalhos (C) & Próprio & $\begin{array}{c}\text { Posto } \\
\text { Termométrico }\end{array}$ & $39^{\circ} 25^{\prime} 06^{\prime \prime} \mathrm{N}$ & $8^{\circ} 06^{\prime} 29^{\prime \prime} \mathrm{W}$ & 99 & $\begin{array}{c}\text { Fundo de } \\
\text { Vale }\end{array}$ & $\begin{array}{c}07 / 02 / 10 \mathrm{a} \\
27 / 03 / 10\end{array}$ \\
\hline $\begin{array}{c}\text { Montes } \\
\text { Cimeiros (MC) }\end{array}$ & Próprio & $\begin{array}{c}\text { Posto } \\
\text { Termométrico }\end{array}$ & $39^{\circ} 25^{\prime} 05^{\prime \prime} \mathrm{N}$ & $8^{\circ} 04^{\prime} 53^{\prime \prime} W$ & 184 & Planalto & $\begin{array}{c}07 / 02 / 10 \text { a } \\
27 / 03 / 10\end{array}$ \\
\hline
\end{tabular}

Quadro 1 - Caracterização das estações meteorológicas, postos udométricos e termométricos automáticos das redes meteorológicas do IPMA, IP, INAG, IP, PEGOP, SA e Próprio. 